\title{
Analysis of enterprises with innovation activity with emphasis on enterprise size
}

\author{
Katarina Janoskova ${ }^{1, *}$, Pavol $\mathrm{Kral}^{1}$ \\ ${ }^{1}$ University of Žilina, Faculty of Operation and Economics of Transport and Communications, \\ Department of Economics, Univerzitna 8215/1, 01026 Žilina, Slovakia
}

\begin{abstract}
.
Research background: Small and medium-sized enterprises (SMEs) play a crucial role in European economic. They are very important for the stability of national economy and for development of innovation. SMEs significantly contribute to innovation because they are under permanent pressure of competitors at the market. On the other hand, innovation in SMEs is hampered by many factors, such as lack of finance, lack of personnel, no experiences, insufficient public policy, etc.

Purpose of the article: The main goal of the article is examining the impact of business size on innovation activity and thus confirm the irreplaceable importance of SMEs in the innovation ecosystem, compare innovation activity of Slovak SMEs with EU average.

Methods: Several methods were used to achieve the goals. Demonstrating the close relationship between innovation and SMEs is realized through VOSviewer software. Comparison of innovation activity of Slovak SMEs with European Union average is realized through an in-depth analysis of selected indicators of Summary Innovation Index.

Findings \& Value added: SMEs are indeed the creator of innovation. Based on the results of bibliometric analysis, this fact can be confirmed. The innovation activity of SMEs in the Slovak Republic is below the EU average. This fact is caused by several limitation and problems that SMEs in the Slovakia have to face.
\end{abstract}

Keywords: innovation; small and medium-sized enterprises; Slovak Republic

JEL Classification: O30; O39; F69

*Corresponding author: katarina.janoskova@,fpedas.uniza.sk 


\section{Introduction}

Small- and Medium-Sized Enterprises (SMEs) play very important role in European economic. More than $90 \%$ of all enterprises in the European Union belong to the category of SMEs. They are very often named as engine of economic. SMEs are very important for the stability of economic environment and for development of innovation. SMEs are important players in the innovation ecosystem, because they significantly contribute to innovation, jobs and growth creation $[1,2]$ as well as in the process towards sustainable development [3]. De Marco et al. [2] call SMEs in Europe as "EU Innovation Champions". SMEs are under permanent pressure of competitors at the market; therefore, they are forced to make innovations. The ability to compete in innovations plays important role as a factor of their competitiveness [4], especially in environmental innovation [5]. For these reasons, innovation, innovation activities, innovation performance, innovation potential etc. in smalland medium-sized enterprises are constantly point of interest by many scholars [6-9].

The situation in Slovak republic is similar, but not the same as in the rest of Europe. SMEs create more than $70 \%$ of workplaces and approximately $60 \%$ of GDP. The rapid development of SMEs in Slovak Republic was after 1990 in connection with privatization (large and small privatization) and the transformation of the economy and was caused by the following facts: i) gradual disintegration of large state-owned enterprises in the process of the first wave of large-scale privatization, ii) return of property to citizens within the restitutions, iii) liberalization of trade relations and the creation of many SMEs with foreign ownership.

The rapid technological change along with increasingly uncertain business and market globalization that occurred in the last decade has a great impact on the competitive business environment. Similar to large companies, small and medium-sized enterprises (SMEs) are complied to continue to strengthen their capacity to face the free market. Market globalization and sharp competition have led to major changes in people's lives. Therefore, companies are required to adapt and apply the right strategies to successfully exploit business opportunities [10]. Innovation is the way to respond to these changes, because entrepreneurship theory considers innovation as a key driver of competitive advantage in the business sector [11, 12], a critical factor for business performance and survival, especially in the case of SMEs [13, 12]. SMEs are commonly defined as reactive, flexible and risky organisations being able to obtain profits from a quicker and more flexible adjustment to environmental changes due to simplified hierarchies and quick decision making [14, 12].

In economic literature, various classifications of innovation have been applied. Innovation represents the process of placing a certain product on the market (goods or services), a new one or a significantly improved one. Innovation focuses on the cooperation between research and industry, due to the need for finalizing the research through practical results related to the technical and technological developments [15].

J. A. Schumpeter who is considered the father of innovation, defined innovation as launch of a new product, application of new methods, opening new markets, acquiring new resources, etc. All these types of innovations allow companies to realize a competitive advantage and economic benefits. Research brings inventions that should be developed and marketed. The inventions that are successfully introduced to the market result in revenues that exceed investments costs. To this approach, the search for new technologies is more important than the adaptation to the existing patterns of demand. Consequently, the technological innovation is a driver of competition and profitability [16].

The importance of SMEs in the context of the innovation process was discussed by $\mathrm{J}$. Schumpeter in one of his pioneer works. He insisted that new, small, entrepreneurial firms are likely to be the source of most innovations searching creatively for the new market opportunities. However, later, he focused on capital market imperfections and claimed that large, mature firms have better access to finance and extensive resources required for $R \& D$ 
projects. Thus, he proposed subsequently that small firms tend rather to imitate than to innovate themselves due to high costs of R\&D activity. Recent studies, however, point out that small firms are quite heterogeneous, ranging from highly innovative firms to traditional ones for which the innovative process is irrelevant. As a consequence, the main determinants of innovation in SMEs are proposed to be: sector belonging, the particular nature of innovation and the characteristics of the firm itself, such as size and age [17].

The main goal of the article is examining the impact of business size on innovation activity and thus confirm the irreplaceable importance of SMEs in the innovation ecosystem, compare innovation activity of Slovak SMEs with EU average. The paper is organized as follows. Chapter 2 describes the methods used to achieve the purpose of the research. Chapter 3 contains main results of bibliometric analysis and in-depth analysis of Summary Innovation Index and discussion of these results. Finally, chapter 4 presents conclusions.

\section{Methods}

To achieve the purpose of the article, several methods were used. Demonstrating the close relationship between innovation and SMEs is realized bibliometric analysis through VOSviewer software. Currently, interest in bibliometric research is growing thanks to information and communication technologies that allow for the processing large amounts of data while providing the means to visualize the results comprehensibly and sophistically, usually in the form of science maps. The knowledge of bibliometric is gradually becoming part of decision-making processes, and it also helps to identify new trends, and this information can also be useful for scientists themselves in their research activities [18,7]. To identify the top 10 innovation-related keywords, the VOS Viewer was used. Aim of this part of research was to determine whether SMEs belong to the most important keywords related to innovation.

Comparison of innovation activity of Slovak SMEs with European Union average is realized through an in-depth analysis of selected indicators of Summary Innovation Index. The basis for the analysis was the European Innovation Scoreboard 2019 report, which shows indicators of innovation performance of EU countries in 2018. The European innovation scoreboard provides a comparative analysis of innovation performance in EU countries, other European countries, and regional neighbours. It assesses relative strengths and weaknesses of national innovation systems and helps countries identify areas they need to address.

\section{Results and Discussion}

\subsection{Bibliometric analysis}

To identify top 10 keywords related to innovation, the VOS Viewer was used to show their occurrence from innovation-oriented journals and conference proceedings from the Web of Science database. In this part, we performed the bibliometric analysis using VOS Viewer tool. Figure 1 shows the network visualization of the top 10 innovation-related keywords. 


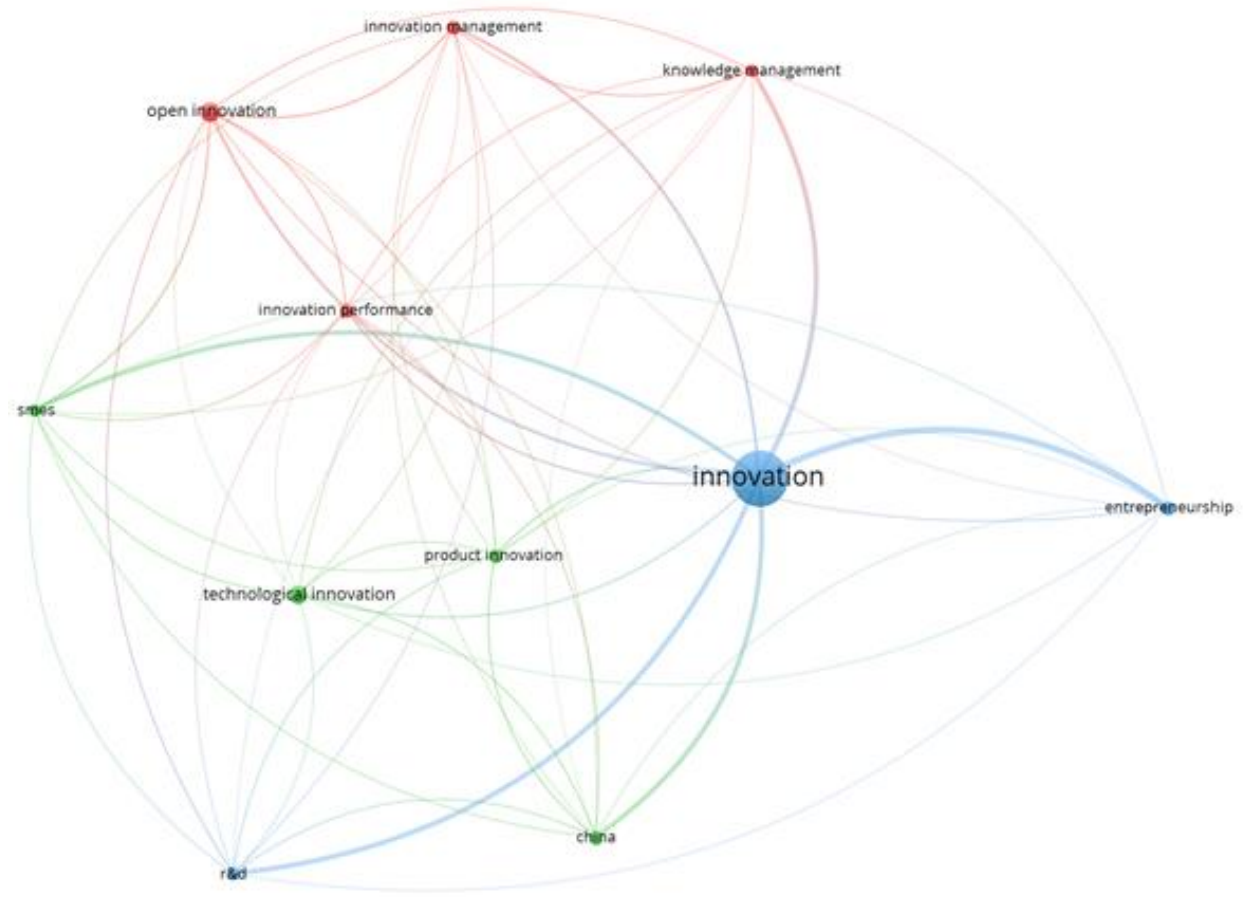

Fig. 1. Top 10 innovation-related keywords Source: own processing usin VOSviewer

The top 10 innovation-related keywords divided into three clusters according to the relationships are in the tab. 1.

Table 1. Innovation-related keywords

\begin{tabular}{|l|l|}
\hline Cluster & Innovation-related keywords \\
\hline Cluster 1 & $\begin{array}{l}\text { open innovation } \\
\text { innovation management } \\
\text { knowledge management } \\
\text { innovation performance }\end{array}$ \\
\hline Cluster 2 & $\begin{array}{l}\text { SMEs } \\
\text { technological innovation } \\
\text { product innovation } \\
\text { China }\end{array}$ \\
\hline Cluster 3 & $\begin{array}{l}\text { entrepreneurship } \\
\text { R\&D }\end{array}$ \\
\hline
\end{tabular}

Source: own processing using VOSviewer

Based of scholar's and our opinion, SMEs are indeed the creator of innovation. Based on the results of bibliometric analysis, this fact can be confirmed. As we can see in the visualization, SMEs are among the top 10 innovation-related keywords.

SMEs are part of the second cluster (tab. 1). It means that SMEs have very close relationship with other three keywords (technological innovation, product innovation, China). 


\subsection{In-depth Analysis of Selected Indicators of Summary Innovation Index}

European Union Scoreboard (Summary innovation index) contains four indicators related to innovation in SMEs:

- SMEs with product or process innovations - number of SMEs who introduced at least one product innovation or process innovation either new to the enterprise or new to their market. A product innovation is the market introduction of a new or significantly improved good or services with respect to its capabilities, user friendliness components or sub-systems. A process innovation is the implementation of a new or significantly improved production process, distribution method, or supporting activity.

- SMEs with marketing or organisational innovations - number of SMEs who introduced at least one new organisational innovation or marketing innovation. An organisational innovation is a new organisational method in an enterprise's business practices (including knowledge management), workplace organisation or external relations that has not been previously used by the enterprise. A marketing innovation is the implementation of a new marketing concept or strategy that differs significantly from an enterprise's existing marketing methods and which has not been used before

- SMEs innovating in-house - number of SMEs with in-house innovation activities. Inhouse innovating enterprises are defined as enterprises which have introduced product or process innovations either themselves or in co-operation with other enterprises or organisations

- Innovative SMEs collaborating with others - number of SMEs with innovation cooperation activities, i.e. those firms that had any co-operation agreements on innovation activities with other enterprises or institutions in the three years of the survey period [19].

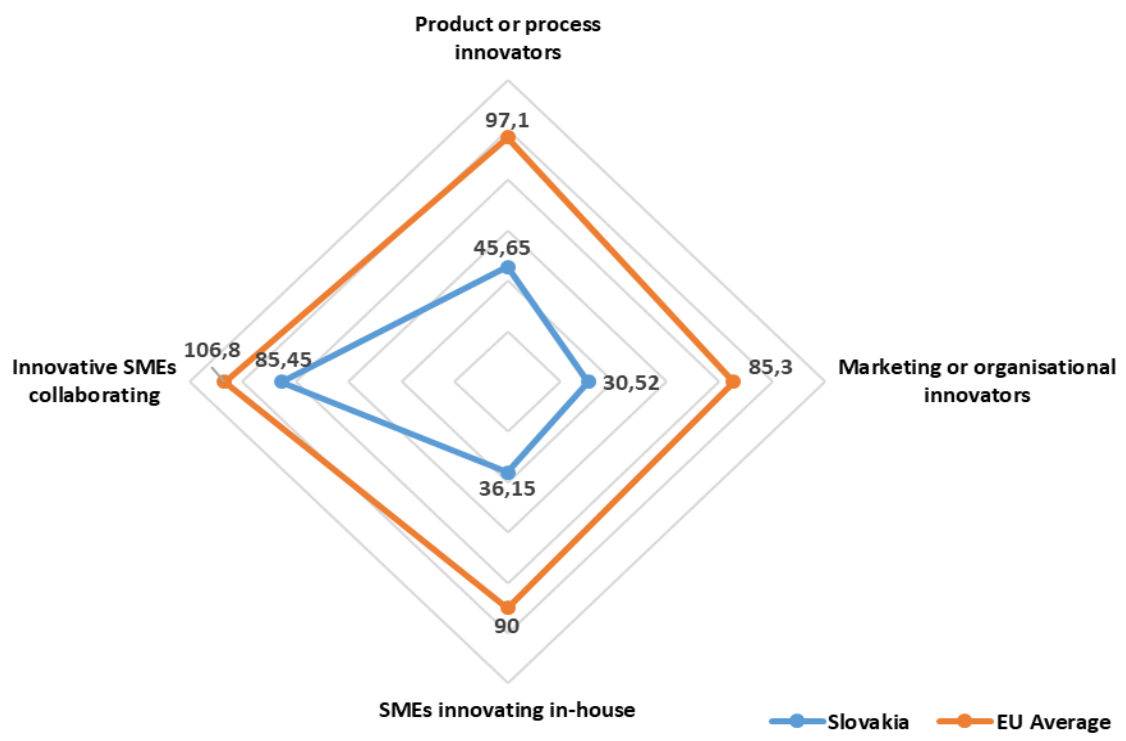

Fig. 2. SII indicators related to innovations in SMEs - 2018

Source: own processing according to the European Union Scoreboard 

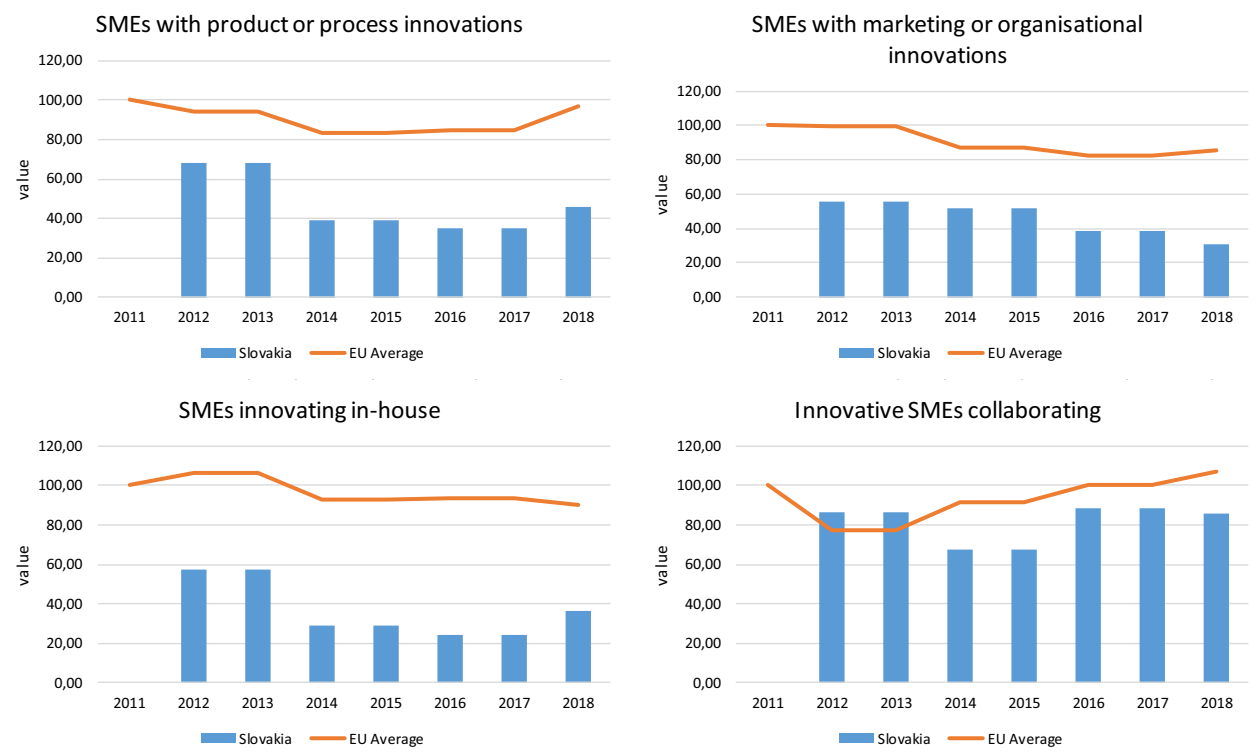

Fig. 3. SII indicators related to innovations of SMEs $2011-2018$

Source: own processing according to the European Innovation Scoreboard 2019 [19]

Based on the European Innovation Scoreboard, Slovakia is a Moderate Innovator. Over time, performance has increased relative to that of the EU in 2011. The current values of all indicator related to innovation in SMEs are below the EU average. The situation in this area is unsatisfactory.

The main reasons why the innovative performance of SMEs in the Slovak Republic is insufficient are the problems typical for SMEs. Many scholars are interested in the issue of constraints related to innovation performance in SMEs. The most common problems are:

- Lack of finance - SMEs generally lack the resources to conduct R\&D in new and emerging fields, namely human resources, information and capital [20]. Internal funds inevitably are limited in the case of SMEs and therefore, firms need to look for external sources of funding if they are to continue with their innovation projects. In this context, the access to regional and national funding could be simplified, in order to reduce the administrative burden and allow greater participation of SMEs [3]. SMEs in comparison to larger firms, are gearing up to take up new and emerging technology-based industries [20].

- Lack of personnel and time [21].

- Little or no experience [21].

- Limited confidence in implementing new systems [21].

- Insufficient public policy, public support and national innovation system - public policy can effectively increase collaboration for innovation among firms, entrepreneurs, research institutions and the public sector in a way that is easily accessible and beneficial for SMEs [22-24].

- Scant opportunities to recruit specialized workers [25].

- Small innovation portfolios so that risks associated with innovation cannot be spread [25]. 


\section{Conclusion}

Innovation is a key determinant of productivity and long-term growth of SMEs. SMEs are, on average, less innovative than large enterprises, but on the other hand, some SMEs are highly innovative and can reach productivity levels above those of large companies. Innovative performance of SMEs in Slovak republic is below the EU average. The main reason why the innovative performance of SMEs in Slovak republic is insufficient are the problems and limitations typical for SMEs. The most serious problem is insufficient government support. Government should support innovation in SMEs in Slovak Republic by fostering a sound business environment, helping SMEs to develop and use their internal strategic resources effectively, and building an innovation system that is effective in the commercialisation of research and inclusive of a large range of SMEs [26].

The contribution is an output of the project VEGA 1/0619/20 Fundamental research of quantitative and qualitative determinants of enterprise innovation potential and innovation performance in relation to increasing its competitiveness.

\section{References}

1. Storey, DJ. (2016). Understanding the Small Business Sector. Taylor \& Francis Group.

2. De Marco, CE., Martelli, I., Di Minin, A. (2020). European SMEs' engagement in open innovation When the important thing is to win and not just to participate, what should innovation policy do? Technological Forecasting \& Social Change, 152, art. no. UNSP 119843.

3. Cecere, G., Corrocher, N., Mancusi, ML. (2020). Financial constraints and public funding of eco-innovation: empirical evidence from European SMEs. Small Business Economics, 54(1), 285-302.

4. Lesakova, L. (2018). The Critical View on Innovation Activity in SME's Sector in Slovakia. Modeling Innovation Sustainability and Technologies: Economic and Policy Perspectives, 137-147.

5. Rashid, AA., Sidek, AA., Suffian, SA., Daud, MRC. (2018). Environmental Management Competitive Pressure Effect on SME Environmentla Innovation Activities: A Green Supply Chain Perspective. International Conference on Advances in Manufacturing and Materials Engineering (ICAMME 2017), vol. 290. Bristol: IOP Publishing.

6. Durana, P., Zauskova, A., Vagner, L., Zadnanova, S. (2020A). Earnings Drivers of Slovak Manufacturers: Efficiency Assessment of Innovation Management. Applied Sciences - Basel, 10(12), art. no. 4251.

7. Durana, P., Valaskova, K., Vagner, L., Zadnanova, S., Podhorska, I., Siekelova, A. (2020B). International Journal of Financiala Studies, 8(1), art. no. 17.

8. Zauskova, A., Lyakina, M., Tretyak, V., Miklencicova, R. (2020). Application of artificial neural networks to cost factors stimulating innovation - The case of Slovakia. Ekonomicko-manazerske spektrum, 14(1), 97-105.

9. Zauskova, A., Reznickova, M. (2020). SoLoMo marketing as a global tool for enhancing awareness of eco-innovations in Slovak business environment. Equilibrium: Quarterly Journal of Economics and Economic Policy, 15(1), 133-150. 
10. Efendi, S., Sugiono, E., Guritno, E., Sufyati, Hendryadi (2020). Building innovation and competitiveness for low technology manufacturing SMEs through imitating capability and learning: The case of Indonesia. Cogent Social Science, 6(1), art. no. 1803515.

11. Madrid-Guijarro, A., Garcia-Perez-de-Lema, D., Auken, H. (2009). Barriers o Innovation among Spanish Manufacturing SMEs. Journal of Small Business Management, 47(4), 465-488.

12. Exposito, A., Fernandez-Serrano, J., Linan, F. (2019). The impact of open innovation on SMEs' innovation outcomes. New empirical evidence form a multidimensional approach. Journal of Organizational Change Management, 32(5), 558-577.

13. Pett, T., Wolff, J. A. (2009). SME Opportunity for Growth and Profit: What is the Role of Product and Process Improvement? International Journal of Entrepreneurial Venturing, 1(1), 5-21.

14. Terzioski, M. (2010). Research Notes and Commentaries Innovation Practice and its Performance Implications in Small and Medium Enterprises (SMES) in the Manufacturing Sector: A Resource-based View. Strategic Management Journal, 31, 892-902.

15. Gherghina, S. C., Botezatu, M. A., Hosszu, A., Simionescu, L. N. (2020). Small and Medium-Sized Enterprises (SMEs): The Engine of Economic Growth through Investments and Innovation. Sustainability, 12(1), art. no. 347.

16. Torok, A., Toth, J., Balogh, J. M. (2019). Push or Pull? The nature of innovation process in the Hungarian food SMEs. Journal of Innovation \& Knowledge, 4(4), 234-239.

17. Blach, J., Wieczorek-Kosmala, M., Trzesiok, J. (2020). Innovation in SMEs and Financing Mix. Journal of Risk and Financial Management, 13(9), art. no. 206.

18. De Bellis, N. (2009). Bibliometrics and Citation Analysis: From the Science Citation Index to Cybermetrics. Lanham: The scarecrow Press.

19. Hollanders, H., Es-Sadki, N., Merkelbach, I. (2019). European Innovation Scoreboard. Retrieved from: ETAY19181ENN.en.pdf

20. Sikka, P. (1999). Technological innovation by SME's in India. Technovation, 19(5), 317321.

21. Albors-Garrigos, J., Etxebarria, NZ., Harvas-Oliver, JL., Epelde, JG. (2011). Outsourced innovation in SMEs: a field study of R\&D units in Spain. International Journal of Technology Management, 55(1-2), 138-155.

22. Leckel, A., Veilleux, S., Dana, LP. (2020). Local Open Innovation: A means for public policy to increase collaboration for innovation in SMEs. Technological Forecasting and Social Change, 153, art. no. 119891.

23. Radicic, D., Pugh, G., Douglas, D. (2020). Promoting cooperation in innovation ecosystems: evidence from European traditional manufacturing SMEs. Small Business Economics, 54(1), 257-283.

24. Caiyan, J., Tang, X., Kan, Z. (2020). Does the Nation Innovation System in China Support the Sustainability of Small and Medium Enterprises (SMEs) Innovation? Sustainability, 12(6), art. no. 2562.

25. van de Vrande, V., de Jong, J. P. J., Vanhaverbeke, W., de Rochemont, M. (2009). Open innovation in SMEs: Trends, motives and management challenges. Technovation, 29(67), 423-437.

26. Promoting innovation in established SMEs. (2018). Retrieved from: 2018-SMEMinisterial-Conference-Parallel-Session-4.pdf (oecd.org) 